\title{
O TOCANTINS E SEU ENSINO DE INGLÊS NA PROPOSTA CURRICULAR PARA O ENSINO MÉDIO: ENTRE EXPECTATIVAS E SILENCIAMENTO
}

\author{
TOCANTINS AND THE ENGLISH TEACHING IN THE \\ CURRICULAR PROPOSAL FOR MIDDLE SCHOOL: BETWEEN \\ EXPECTATIONS AND SILENCING
}

Gilberto Alves Araújo*

\begin{abstract}
Resumo: Este artigo pretende identificar representações discursivas na Proposta Curricular (PC) do Tocantins para o Ensino Médio (TOCANTINS-SEDUC, 2009), tanto no que concerne aos autores desse documento, à língua estrangeira, ou mais especificamente ao ensino escolarizado de língua inglesa, quanto ao papel desempenhado pelos docentes dessa disciplina. Para tanto, utiliza concepções de Pêcheux $(1995 ; 1997 ; 2006)$ acerca de esquecimento, assujeitamento, formações ideológica e discursiva, bem como os procedimentos metodológicos de análise propostos por Orlandi (1998; 1999). A PC projeta o ensino de língua inglesa em um extenso horizonte de expectativas com relação à sua significância; tende a sobrelevar o discurso científico e literário na medida em que procura reservar o silêncio à voz do docente em sua prática cotidiana. No sistema econômico (ou em seu uso/utilidade), busca as respostas para os porquês do ensino desse idioma no Tocantins. Por fim, a identidade dos sujeitos redatores do documento surge entre inteireza e dispersão.
\end{abstract}

Palavras-chave: Discurso. Língua inglesa. Proposta Curricular. Tocantins.

\begin{abstract}
This article aims at identifying discursive representations through Tocantins State Curricular Proposal (CP) for High School (TOCANTINS-SEDUC, 2009), regarding not only authors of that document, and English teaching at school, but also the role played by teachers. It uses Pêcheux's conceptions $(1995 ; 1997 ; 2006)$ towards forgetting, subjection, ideological and discursive formation, as well as methodological procedures proposed by Orlandi $(1998 ; 1999)$. CP projects English teaching into an extensive horizon of expectations in relation to its significance; tends to overestimate scientific/literary discourse as it silences teacher's voice in her/his everyday practice. CP also searches for answers in the economic system (in its use/usefulness) in order to explain the reasons for teaching English in Tocantins. Lastly, the identity of subjects who elaborated the document emerges between entirety and dispersion.
\end{abstract}

Keywords: Discourse. English Language. Curriculum. Tocantins.

\section{Introdução}

Este texto se trata do recorte de uma dissertação de mestrado (ver. ARAÚJO, 2014), defendida no âmbito de um dos programas de pós-graduação da Universidade Federal do Tocantins (Mestrado em Ensino de Língua e Literatura-MELL), na qual pudemos trabalhar em maior profundidade e extensão as relações de representação entre o discurso docente, a disciplina de língua inglesa na escola, e a Proposta Curricular do Estado do Tocantins referente a esta matéria, dentre outros tópicos. Sendo assim, em face do espaço aqui definido, nosso objetivo com o presente trabalho limita-se a apresentar algumas representações discursivas construídas nesse documento acerca do ensino de língua estrangeira, do docente e dos próprios autores da proposta.

O documento selecionado para este estudo - Proposta Curricular do Tocantins para o Ensino Médio: Versão Preliminar (doravante PC) - foi produzido sob condições adversas, em distintos momentos históricos e espaços sociais (TOCANTINS-SEDUC, 2009). Essas

\footnotetext{
* Professor Assistante na Faculdade de Letras, Universidade Federal do Pará (UFPA), Brasil; PhD Candidate at The University of the Witwatersrand (WITS), South Africa.
} 
circunstâncias enunciativas, como os preocupantes resultados do estado no ENEM $^{1}$ (Exame Nacional do Ensino Médio), e a política econômica e educacional do país ${ }^{2}$ diante da UNESCO (Organização das Nações Unidas para Educação, Ciência e Cultura), do Banco Mundial e do FMI (Fundo Monetário Internacional), por exemplo, afetaram de maneiras diversas um número considerável de locutores e interlocutores que colaboraram na construção dessa proposta, como apontaremos a seguir na discussão sobre os efeitos do capitalismo e do silenciamento no discurso da PC.

Essa PC é relativamente recente, redigida a partir de 2005, e finalizada/publicada em 2009. No momento de sua 'discussão' e 'elaboração' os habitantes do Tocantins eram impactados pelos resultados do ENEM, que apontavam um fracasso da educação pública praticada nesse território. Entre 2007 e 2010, os alunos de nosso Estado oscilaram entre o último e o antepenúltimo lugar no ranking nacional. Se os debates sobre a educação nacional apontavam que o insucesso era geral, os sentidos de que o Tocantins se fazia o pior dos piores circulavam com bastante intensidade nos discursos midiático e político-partidário, como podemos perceber a partir das sessões da Assembleia Legislativa tocantinense (ASSEMBLEIA LEGISLATIVA-TO, 2008a; 2008b), dos requerimentos referentes ao assunto (idem, 2008c), e das manchetes de jornal no período (G1 NOTÍCIAS, 2008).

\section{Pressupostos teóricos e metodológicos}

Antes de discorrer sobre nossos procedimentos/etapas específicos de análise, apresentamos alguns princípios teóricos e/ou concepções básicas que orientam este trabalho. Dentre estes, destacamos os conceitos de polissemia, paráfrase, metáfora e antecipação, bem como as noções de Formação Discursiva (FD), esquecimento (número um e número dois), Formação Ideológica (FI), e assujeitamento, que por sua vez se subdivide em processos de identificação, desidentificação e contraidentificação - estas concepções são explanadas a seguir, e seus pontos-chave estão grifados em itálico para facilitar sua localização pelo leitor.

A saber, Pêcheux (1995, p. 160) concebe FD como um projeto de coesão e coerência, que, sob certa conjuntura e estado de luta de classes, "determina o que pode e deve ser dito (articulado sob a forma de uma arenga, de um sermão, de um panfleto, de uma exposição, de um programa etc.)". Por outro lado, o estudioso nota que a pretensa homogeneidade ou univocidade da FD seria, de fato, um simulacro, pois sua natureza essencial é heterogênea, considerando que a ideologia é constante interpeladora do sujeito, o que afeta/altera significativamente os discursos e suas condições de manifestação.

Intimamente ligados às FDs encontram-se dois processos essenciais à reprodução e circulação de discursos, duas espécies de esquecimento que interveem na constituição do sujeito, ou seja, em suas filiações a determinadas FDs. A primeira espécie ou primeiro tipo de esquecimento é inconsciente e ideológico, e permite ao sujeito fazer de si mesmo a fonte de tudo o que diz, denegando tudo o que não se insere na sua FD. Essa manobra concede ao sujeito

\footnotetext{
${ }^{1}$ Em 2005 e 2006 o Tocantins alcançou a $26^{\text {a } ~ e ~ a ~ u ́ l t i m a ~ p o s i c ̧ a ̃ o, ~ r e s p e c t i v a m e n t e, ~ e n t r e ~ a s ~ u n i d a d e s ~ d a ~ f e d e r a c ̧ a ̃ o ~}$ (BRASIL, 2007). Já em 2007 o estado obteve a última colocação, com 41,98 nas provas objetivas (G1 NOTÍCIAS, 2008). Em 2008 e 2009 Tocantins apresentou uma média ponderada, entre redação e prova objetiva, de 45,58 e 50,05, o que o deixou em último e penúltimo lugar respectivamente (idem, 2010).

${ }^{2}$ Como exemplo dessa política, mencionamos o Consenso de Washington (ver. SYMONIAK, 2011), entre outras elaboradas no âmbito de organismos internacionais (ver. BANCO MUNDIAL, 1992; 1995; UNESCO, 1990; 2000).
} 
a sensação de que ele é um enunciador adâmico ${ }^{3}$, conforme explica Bahktin (1997). A segunda espécie ou segundo tipo de esquecimento é anteconsciente ou quase consciente, e consiste no fato de que o sujeito, na seleção de dizeres, prestigia certas formas e procura eliminar outras. Por meio dessa operação, ele acredita na univocidade de sentido do seu dizer. Trata-se de uma peleja contra a heterogeneidade, e um anseio pela coerência e coesão do seu ser, e dizer-fazer.

Porém, precisamos lembrar que a FD é sempre afetada pela memória dos dizeres ou pela historicidade dos enunciados. Diante disso, ela confere ainda mais instabilidade e dispersão aos sentidos que se lhe produzem.

Outrossim, não nos podemos esquecer de que, além das condições de produção, as FDs e os sujeitos que nelas se fazem estão diretamente relacionados ao ideológico ou às formações ideológicas (FIs), concepção apresentada adiante.

Quanto à FI é preciso, primeiramente, notar que esta é composta de várias FDs. Essa relação somente é possível porque as FIs são superestruturas ainda mais abrangentes e, muitas vezes, sutis, capazes de direcionar não apenas as práticas discursivas, mas também seus sujeitos. Formalmente, as FIs podem ser entendidas como um agrupamento complexo de atitudes, práticas de significação e, por conseguinte, representações mais ou menos ligadas ao posicionamento de classes, que se encontram sempre em conflito com outra[s] (PÊCHEUX, 1997). Em última instância, a FI pode ser tomada como um conjunto de práticas modais de acessar, interpretar, experienciar o mundo, o princípio motor capaz de determinar/delinear embates entre classes sociais. Cada um desses conjuntos é também construído a partir da realidade e das relações que cada classe mantém com as outras, consigo, com a história e a linguagem, ao passo em que estes elementos a determinam.

Através desse processo em que a ideologia interpela o indivíduo para torná-lo sujeito, entendemos que as FDs perfazem a materialização linguística das FIs que, por sua vez, determinam o que deve e/ou pode ser dito em dada formação social. Em termos mais pragmáticos, diríamos que a significância das expressões linguísticas provém das FDs, que em seu turno possibilitam a materialização das FIs (PÊCHEUX, 1995).

Por isso a concepção de sujeito na AD indica que este agente discursivo é assujeitado, disperso, cindido e inconsciente; porque a FI, enquanto superestrutura pré-construída e, portanto, anterior ao sujeito, afeta-o de tal maneira que não permite existir um pretenso controle ou intenção idiossincrática por sua parte (PÊCHEUX, 1995).

Notamos que essa interpelação ideológica só se torna operável graças ao processo de identificação que há entre o sujeito e a FD que o determina. Este procedimento, por sua vez, faz com que a língua não funcione igualmente cada vez que é tomada pelo sujeito, pois varia a identificação de sujeitos com suas FDs, bem como as condições de produção do discurso. Eis aí um dos fatores que promove o deslocamento do sujeito e dos seus modos de assujeitamento.

Nesse sentido, o assujeitamento é, em parte, fruto dos diversos processos de identificação, isto é, resultado do trabalho da ideologia em interpelar o indivíduo em sujeito, conforme apresentado adiante (modalidades de assujeitamento). Assim, essa interpelação ocorre de modo que o indivíduo se submete à matriz discursiva/FI, que, por sua vez, passa a dominá-lo, e lhe produz no imaginário a ideia de transparência do sentido, e origem do eu, conforme defende Pêcheux em Semântica do Discurso (1995).

Nessa obra, o teórico nos explica que em seu processo de identificação o sujeito é coagido pela ordem do simbólico e pela historicidade. Enquanto isso, noutro nível mais local,

\footnotetext{
3 “Um locutor não é o Adão bíblico, perante objetos virgens [...]. A idéia simplificada que se faz da comunicação [...] leva a evocar a imagem desse Adão mítico. [...] Na realidade, [...] todo enunciado [...] sempre responde, de uma forma ou de outra, a enunciados anteriores. O locutor não é um Adão, e por isso o objeto de seu discurso se torna, inevitavelmente, o ponto onde se encontram as opiniões de interlocutores imediatos [...] ou então as visões do mundo, tendências, teorias" (BAKHTIN, 1997, p. 320).
} 
contextual/específico, esse sujeito assoma como enunciador que assume posições relacionais diversas, por meio das quais vai se reconhecendo ou se narrativizando em certa unidade identitária. Em síntese, diríamos que à medida que se constituem 'forma', os sujeitos vão se deslocando por posições que ocupam/projetam, regidos pelas forças que lhe são coercitivas e situacionais - daí forma-sujeito e posição discursiva.

Esclarecemos que essa forma-sujeito (sujeito do saber, histórico ou universal) se refere à maneira pela qual o sujeito se identifica com a FD que o constitui, determina-o e lhe possibilita a ilusão de unidade - sobretudo nesse ponto intervêm o inconsciente e os esquecimentos sobre os quais discorremos anteriormente.

A posição-sujeito (sujeito enunciador), por sua vez, trata-se de uma plataforma relacional, um mapa imaginário através do qual é possível visualizar os lugares sociais que o sujeito vai assumindo no processo de mobilização discursiva ou assujeitamento (perante as FDs ou FIs) (PÊCHEUX, 1995). São esses entremeios, essas conexões complexas e, em último grau, os efeitos de sentido engendrados nesse contexto de relação de forças ou dizeres, que nos permitem supor quem "é" e o que faz esse sujeito.

Tanto a constituição, quanto a relação entre a forma-sujeito e posição-sujeito, são apreensíveis através das modalidades de subjetivação/assujeitamento, ou seja, através das maneiras de reverberação, alteração e incorporação de efeitos pré-construídos que determinam os sentidos dos dizeres de cada sujeito.

Para Pêcheux (1995, p. 213-270), essas modalidades de assujeitamento são três. A primeira consiste na identificação dos saberes que caracterizam o sujeito universal com o pretenso indivíduo que se arraiga e se reconhece no interior de uma FD. Essa identificação é tão plena e eficaz que, de dentro de suas posições, o sujeito se enxerga como enunciador, como senhor de seu próprio dizer.

A segunda reflete um movimento de contraidentificação (resistência passiva) do sujeito enunciador contra o universal. Mediante a inquirição e a dúvida, a altercação, a revolta, a conjunção com outras FDs/FIs, o enunciador, embora não negue os conhecimentos do seu ser universal, passa a conferir outros sentidos aos saberes e valores que o determinam. Ele continua envolto em sua forma-sujeito, portanto, seu mover dentro dela torna-se uma relação contraditória - uma resistência pontual.

A terceira pressupõe a íntima relação entre ciência, identidade e formação políticoideológica, sendo que o último elemento é capaz de fortemente determinar o primeiro, o que contraria o discurso de neutralidade das ciências.

De fato, a modalidade supracitada é bem mais profunda e densa, tanto em relação a um aparente fortalecimento do sujeito enunciador quanto a uma oposição deste à forma-sujeito. Isso acontece porque nessa subjetivação o empenho de transformação/deslocamento por parte enunciador tem por objetivo, não mais a contestação, mas o rearranjo/reordenamento de sua respectiva forma-sujeito (PÊCHEUX apud Grigoleto, 2003).

Esse último movimento é denominado por Pêcheux como desidentificação ou resistência ativa - termo usado para caracterizar uma espécie de assujeitamento em que o sujeito se rebela contra uma FI, deslizando para outra -, um processo no qual o enunciador torna-se sujeito da ciência, apropria-se das concepções dessa, de seu discurso pretensamente neutro para reidentificar-se sob outra formação político-ideológica que determina toda $e$ qualquer produção científica. Aliás, Marx (2010) também entende que a ciência não é neutra e funciona como reprodutora de princípios ideológicos, sobretudo os capitalistas. Trata-se de uma dinâmica paradoxal, como sugere Grigoleto (2003), na qual o sujeito procura reorganizar sua forma universal, reordenando o arcabouço ideológico que o dominava para novamente identificar-se, só que agora com outra FD e com a forma-sujeito correspondente desta.

Seja na identificação, contraidentificação, na desidentificação ou reidentificação, o sujeito vai-se desdobrando, afetado pela rede de relações assimétricas, beligerantes e 
interpenetrantes que colaboram na construção do simulacro do sujeito-enunciador e de outro, o universal. Isso quer dizer que, ao contrário do que muitos possam pensar, essa identidade não parece ser harmônica ou sólida, sendo ilusória a sensação que experimentamos de possuir uma essência identitária: "se sentimos que temos uma identidade unificada do nascimento à morte, é somente por que construímos a consoladora história ou "narrativa de si' sobre nós mesmos" (HALL, 1995, p. 598).

Assim, sob essa perspectiva qualitativa, nossa pesquisa parte primariamente da interpretação, portanto, trata-se de uma abordagem qualitativo-interpretativista. Isso quer dizer que nossa metodologia visa ao tratamento de dados inerentemente subjetivos, como os discursos e os elementos que neles/a partir deles se constituem e se movem, a exemplo das representações, projeções, fenômenos semânticos, valores, posicionamentos ideológicos, performances sociais e hábitos (LAKATOS \& MARCONI, 1993; DENZIN et al, 2006).

No que se refere à interpretação, Pêcheux (2006) nos ensina que não há descrição, explicação ou exploração neutra dos acontecimentos ou objetos. Toda linguagem é constituída pelo equívoco, porque os enunciados são sempre passíveis a se tornarem outros. E todos eles podem ser descritos em uma série determinada, suscetíveis a prováveis pontos de deriva que, por sua vez, oferecem lugar à interpretação - daí a necessidade de assumirmos o viés interpretativista de nosso trabalho.

Segundo esse teórico, a interpretação se constitui em gesto, quer dizer, um movimento ou um conjunto de atos dentro da ordem simbólica. Esta é naturalmente incompleta, marcada pela relação com o silêncio (PÊCHEUX, 1995). Nesse sentido o papel do analista seria constituir o "vestígio do possível", e, interpelado pelas FIs que o determinam, reerguer sua relação com a história, com o interdiscurso ${ }^{4}$, onde a interpretação é materializada e exposta (ORLANDI, 1998, p. 15, 18).

Nossos movimentos poderão partir da matéria linguística para as condições de produção e vice-versa. Desta maneira, pretendemos abordar os gestos interpretativos dos sujeitos a partir de suas posições, para que possamos expor as ligações entre tais gestos, localizando contradições/identificações discursivas, retornos e deslocamentos.

Quanto aos procedimentos de análise, adotamos três estágios básicos que desdobramos a seguir (ORLANDI, 1999). O primeiro estágio - escolhemos este termo [estágio] ignorando sua acepção relativa ao tempo para nos basear na ideia de ensaio, prática, experimentação, tentativa ou aposta, conforme defende Morin (2008) - constitui-se no movimento da concretude linguística para a FD, com seus elementos de sentido, seus percursos, efeitos e valores. Em outras palavras, diríamos que nessa primeira incursão precisamos estar atentos a fenômenos como a paráfrase, a polissemia, a metáfora e a antecipação.

De certo modo, esses fatos do discurso apontam para uma tensão que se catalisa entre reprodução e multiplicação de sentidos, entre unitas e multiplex ${ }^{5}$, ou entre paráfrase e polissemia. Enquanto esta (a polissemia) diz respeito às possiblidades de efeitos de sentido, ao

\footnotetext{
${ }^{4} \mathrm{O}$ interdiscurso consistiria no processo pelo qual o sujeito opera o relacionamento complexo entre os usos da linguagem e as FD; ou seja, é o interdiscurso que permite ao sujeito operar contra a subjetivação da linguagem, e lhe permite gerar uma sequência discursiva, assumindo mais objetos de certa FD do que de outra, fazendo destes elementos de seu 'próprio' discurso, embora eles estejam ligados ou pertençam a outros autores, falantes ou comunidades, épocas ou espaços (PÊCHEUX, 1995).

${ }^{5}$ Unitas multiplex pode ser considerada um princípio filosófico de compreensão acerca do mundo, ou dos seres, e fenômenos da natureza e da cultura. Sob essa perspectiva, diversidade e heterogeneidade dos componentes de um ser ou evento passam a ser analisados do ponto de vista de um conjunto uno e homogêneo. Com efeito, o todo tanto pode ser "mais que as [suas] partes; [quanto] as partes [...] mais que o todo". Isso ocorre porque a interação entre essas unidades pode fazer emergir algo novo no conjunto, tornando-o então mais amplo do que antes. Por outro lado, as partes podem ser mais que o todo pelo fato de que este restringe certas idiossincrasias daquelas, que por sua vez, a fim de integrar esse conjunto, precisam reprimir algumas de suas propriedades e características (MORIN, 1987, p. 102).
} 
desvio, à falha, ao equívoco e à quebra do percurso de significação, aquela (a paráfrase) nos ajuda a identificar os traços da memória do discurso, os elementos que servem de base às (re)formulações de um dizer consolidado na história e na linguagem.

Ademais, cabe-nos ressaltar que a paráfrase é primordial para a abordagem da memória do dizer e, portanto, do interdiscurso. Ela pode nos permitir enxergar matrizes de sentido, ou as FDs, que inserem o dizer na historicidade e concedem ao sujeito a percepção ilusória de que é ele mesmo a fonte de seu próprio discurso.

Já a metáfora é um processo de reinserção de coligações significantes em outro contexto. Um recurso que conecta língua e discurso, denunciando a dialética entre estrutura e acontecimento, apontando, em último nível, a FI que a determinou (PÊCHEUX 1997; ORLANDI, 1999).

Por fim, a antecipação é um mecanismo que permite ao sujeito colocar-se no lugar do outro com quem ele entra em relação. O sujeito supõe que sentidos seu interlocutor irá mobilizar e assim vai conformando seu dizer, ajustando as imagens que produz e modalizandose no intuito de perfazer um jogo complexo e profundo. Baseado nas representações, e naquilo que ele acredita saber sobre o outro, é que o sujeito do discurso tenta regular suas expressões. Tanto a posição da qual o sujeito fala, quanto a posição daquele com quem ele fala, além das condições de produção, interferem nessa regulação do dizer. Nesse processo regulatório o sujeito não apenas opera seleções ou decisões, firmado em simulacros, bem como configura crenças, orientado por simulações. Usando o léxico-semântico da língua francesa, diríamos que a antecipação se faz através de en jeu (um jogo) em que o sujeito se lança em enjeu (aposta) essa dinâmica não deve ser negligenciada em nossa análise.

O segundo estágio trata do movimento entre as FDs e as FIs ou o processo discursivo mais amplo. Nesta etapa nosso papel será identificar a plataforma imaginária comum que une essas FDs, considerando a produção linguística que é a PC, seus autores e o momento ou espaço sócio-histórico em que esse documento foi elaborado. Neste ponto surge a dúvida a respeito da determinação de mais de uma FI sobre as diversas FDs. Orlandi (1999) e Pêcheux (1997), até onde pudemos investigar, admitem a existência de mais de uma FI, porém, parece-nos que para cada conjunto de FD apenas uma FI o conforma - no caso em análise, cremos que seja a FI capitalista (grosso modo). Diante disso, nosso percurso analítico neste procedimento é relativizar as FDs a uma FI, sendo esta responsável por aquelas, em última instância.

Ao atingirmos o nível imaginário, já estamos no terceiro estágio, e, portanto, temos uma visão mais ampla da constituição e organização discursiva que (re)produzem sentidos, tanto na dimensão empírica, quanto simbólica. Esse estágio pode ser entendido como uma estrutura de resultados construídos ao fim de todos os procedimentos anteriores (ORLANDI, 1999). É assim que chegamos a contemplar um sistema aberto e incompleto, como requer o Paradigma da Complexidade ${ }^{6}$; uma apreensão localizada de FD e de uma FI em interação com os sujeitos sobre os quais elas se impõem.

\footnotetext{
${ }^{6}$ Paradigma da Complexidade refere-se a um conjunto de teorias - ou estruturas de pensamento que constituem o padrão de produção, organização, validação e compartilhamento do saber que, por sua vez, decorre das profundas transformações científicas - que veio impactar o pensamento humano a partir do século XIX. Esse paradigma oportuniza a formação de uma nova maneira de entender e pensar o mundo, os homens e a ciência por estes desenvolvida, aceitando o caos como processo necessário e revelador, a compreensão do homem como ser distinto e ao mesmo tempo integrante dos ciclos da vida no planeta; assumindo a contradição e a unidade-diversidade como faces da mesma realidade. Enfim, o entendimento de que sujeito e universo são intrincadamente relacionais e complementares sob os auspícios do previsível e principalmente do imprevisível (MORIN, 2008).
} 


\section{A proposta curricular: imagens de si}

Observamos que o texto introdutório da PC constitui-se da inserção do poema de Fernando Pessoa ${ }^{7}$. Essa ação não é fortuita. Se analisarmos os possíveis sentidos que esse trecho do poeta português possa suscitar, chegaremos a algumas conclusões. De um lado interpretamos a associação dos locutores ao princípio sistêmico e hologramático da complexidade, em que a "terra" está dentro do "universo" e este na primeira. Há também um comprometimento com o Paradigma da Complexidade, especialmente com a visão ecossistêmica, em que os povos, os Estados, ("a aldeia") são solidários e colaborativos entre si, não sendo um superior ao outro, mas partes igualmente integrantes e respeitáveis ("como outra terra qualquer"). Além disso, a noção de que o ponto de vista do sujeito constrói a si e aos objetos, parece indicar uma identificação com a FD Científica, a de teor Complexa, segundo a qual subjetividade e objetividade se integram e se complementam, não havendo fronteira pontual tangível entre essas duas dimensões. Observemos o excerto 1:

1. 'Da minha aldeia vejo quanto da Terra se pode ver no Universo... Por isso a minha aldeia é tão grande como outra terra qualquer Porque eu sou do tamanho do que vejo'. (Fernando Pessoa)

Tocantins, rica terra, abundante água! Coração do Brasil. Coração que 5.pulsa com a força do sangue índio, do sangue negro, do sangue branco, do sangue mestiço, sangue do homem e da mulher de todos os pontos que conduzem ao centro... E aqui, sujeitos da história! E que história! No ano em que o Estado alcança a maioridade (dezoito anos), decisões e ações pertinentes com a maturidade, a força e o vigor da 10.sua idade! Decisões e ações dignificantes! Decisões e ações que se inscrevem na história como verdadeiras epopéias. Do estado do Tocantins, terra da transição entre o cerrado e a floresta amazônica, olhamos para este imenso país, perscrutando em trezentos e sessenta graus, toda beleza natural, todo patrimônio sociocultural, todo 15.investimento político-econômico, bem como todos os subprodutos menos nobres da história de quinhentos e seis anos de construção como nação.

Do estado do Tocantins, terra do sol escaldante, da chuva fecundante; definimos, e buscamos construir e viver, de forma poética e 20.antropoética, o projeto social onde cabem todas as cores, todas as vozes, todas as crenças e todos as presenças.

Do estado do Tocantins, terra da lua que da serra desce a beijar o rio, discutimos, refletimos e acordamos o projeto educativo focado no grande projeto social na perspectiva de contribuir, sobretudo com os 25.jovens, para que todos, sem exceção, estejam nele incluídos, como sujeitos, que coletivamente, e de forma intergeracional, participam da construção da dignificação da vida humana e da preservação e recuperação do ambiente natural onde tudo acontece.

Para o Tocantins, como parte deste projeto educativo, apresentamos o 30.presente documento, a Proposta Curricular do Ensino Médio, que, juntamente com a do Ensino Fundamental, passa a constituir a Proposta Curricular da Educação Básica deste Estado.

Nas linhas de 4 a 21, excerto 1 acima, observamos como os outros elementos interdiscursivos parecem ir-se entretecendo à colcha de retalhos que é o texto da PC. São vozes não declaradas, mas que fortemente constituem o dizer dos locutores do Estado, ou pelo menos

${ }^{7}$ PESSOA, F. O guardador de rebanhos: parte VII. In: Poemas de Alberto Caeiro. Lisboa: Ática, 1993. 
de seu corpo técnico-científico: o discurso jurídico da maioridade penal e civil em atos da vida pública (linha 8); o da ciência geográfica (linhas 12-14); e o da vida como processo biológico (linhas 26-28); o discurso político da diversidade e da inclusão da multiplicidade (linhas 5-7; 20-21; 25-26).

Este último discurso (linhas $5-7 ; 20-21 ; 25-26)$ poderia ser considerado, na visão de Pechêux (1995), uma resistência pontual (contraidentificação). Uma postura que, diante da FI sob a qual vive a sociedade ocidental, não causa de fato uma revolução, mas tão somente um marco de discórdia. De modo geral, resistências dessa natureza, ao invés de desidentificarem os sujeitos, apenas operam a permanência da mesma FI.

A partir da linha 4, temos uma série de metáforas e paráfrases que reiteram os atributos naturais do Estado, ressignificados no discurso, para fazer do Tocantins uma comunidade, uma unidade imaginariamente e contraditoriamente constituída no múltiplo (excerto 1, linhas 5-7). Eis aí o trajeto de constituição identitária na pós-modernidade de que nos fala Stuart Hall (1995; 1996), em que os traços físicos e biológicos ganham representação na atmosfera antropológica.

Com efeito, tanto a PC, com seus vários sujeitos-autores, quanto a imagem do estado de Tocantins se lançam nesse percurso em busca da afirmação de suas próprias identidades. Assim, todas elas se imbricam, como um todo orgânico e ecológico, em que as partes compõem o todo, ao mesmo tempo em que são por ele constituídas.

Para se consolidar esse processo constitutivo recorre também à paráfrase, pois nas linhas 4, 11, 18-20 e 22 (excerto 1) há uma retomada do discurso literário semelhante ao de José de Alencar (1829-1877) em O Guarani ${ }^{8}$, ou ao conceito do 'Bom Selvagem' de JeanJacques Rousseau (1712-1778).

A propósito, esse efeito de sentido é ocasionado pelo contato entre as sociedades mercantilistas, com sua burguesia nascente, e as Américas ainda não subjugadas por essa FI. Sob determinação desta última (FI), as sociedades europeias desenvolveram, à época do "descobrimento" deste continente, a noção de civilização e progresso iluminista. Por conseguinte, tanto do ponto de vista prático, quanto do científico e filosófico, os europeus agem para com as colônias sob duas tendências: uma de superioridade, na qual artefatos tecnológicos, modos de ser e viver europeus seriam mais evoluídos, portanto, mais aceitáveis; e outra de deslumbramento e admiração em face do exotismo com o qual se deparavam.

No entanto, na FD dos literatos, como José de Alencar, e também na PC, há a incorporação e certa prevalência dessa segunda tendência, de modo que aquele choque de civilizações, ou talvez de civilizados e "bárbaros", alcança ares idílicos, nos quais o índio ou o nativo é a forma boa e plena da humanidade, à beira da corrupção pela sociedade civilizada. Resta-nos, então, imaginar se os lugares desses indígenas seriam agora ocupados pelos tocantinenses, caracterizados por esse discurso da PC.

Nesse ponto, o texto da PC, em busca da hegemonia do sentido e da harmonização dos elementos do discurso sobre os quais constrói 'autoria', parece contrastar no intradiscurso ${ }^{9}$ a noção de homem/paisagem selvagem/natural (excerto 1, linhas 1-6, 16, 22) e civilizado(a)

\footnotetext{
8 Em O Guarani, o autor empreende um discurso que intenta estabelecer uma cultura e uma identidade propriamente brasileiras, distinguindo-as em relação ao colonizador, Portugal. Nesse sentido, a terra, com todos os seus exuberantes atributos, bem como seus autóctones, os indígenas, são eleitos como símbolos nacionais. À representação desses povos são integrados estes valores que se deseja imputar à gente do Brasil: coragem, honra, lealdade, devoção e relações afetivas com a natureza. Provavelmente como uma ressonância da filosofia de Rousseau, as personagens e suas culturas indígenas são explicitamente idealizadas, e projetadas a partir das noções de pureza, inocência ou incorruptibilidade.

${ }^{9}$ A articulação que o sujeito, dentro de seu enunciado, opera entre objetos materiais - sejam eles elementos linguísticos, ideológicos ou simbólicos - pode ser entendida como intradiscurso, um tipo de realização/percepção imagética que qualquer sujeito poderia reconhecer sob o signo da pretensa coesão e unidade (PÊCHEUX, 1995).
} 
(linhas 23-26). Podemos ver, lado a lado, uma subjetivação universal, à medida que os locutores se deixam interpelar pela FI crendo na univocidade do que dizem (sem questionálo), e também uma subjetivação desidentificatória, na qual os locutores são impelidos a respeito e aceitação da diferença, bem como ao relativismo cultural, que nada mais é do que a transposição do mito do bom selvagem em ciência.

É aqui que entra a noção das metáforas que são internas às paráfrases. Possivelmente essas 'figuras de discurso/linguagem' quanto à natureza, ao homem e ao nativo foram transportadas do discurso colonial/literário para o discurso ecológico (excerto 1). Deslocados de uma FD do "descobridor" para outra FD científica do "descoberto", os efeitos de sentido daquelas figuras foram levemente alterados. E nós percebemos que houve o efeito metafórico e não apenas parafrásico, primeiro porque mesmo nas obras literárias (fonte da paráfrase), essas figuras já são metáforas, e segundo porque uma palavra em especial (que mostraremos no parágrafo seguinte) nos permite entender que alguns sentidos foram transportados e não apenas reformulados/reinscritos.

A agradabilidade em torno do cerrado, da lua, do beijo do rio, da floresta amazônica e do sol passa agora a ser reinterpretada em virtude de um vocábulo aparentemente falho e contrastante, "escaldante" (excerto 1, linhas 18-19); um vocábulo que pode indicar o funcionamento do esquecimento número dois, no qual pela seleção da forma crê-se na unidade do sentido, e é nesse ponto, então que surge o caráter polissêmico da linguagem. As palavras não são exatamente as mesmas cada vez que pronunciadas, porque o intradiscurso faz-se outro, assim como as relações de identificação no interdiscurso também se fazem outras.

Talvez seja possível notar um forte deslizamento interior a esse mecanismo de paráfrase, em que, na identidade nacional, tenta-se distinguir o Tocantins para depois sedimentar sua identidade a partir de seus limites territoriais. Como exemplo dessa dinâmica há um jogo da imagem do Tocantins (linhas 7-10) com a imagem de um Brasil cronologicamente velho (linhas 15-18). Trata-se de uma manobra comum na constituição discursiva de identidades, a emersão do ser-fazer unívoco pela distinção deste perante os demais.

Com esse propósito, os locutores da PC parecem recorrer à idade oficial histórica, para inscrever o Tocantins na ordem simbólica da identidade que se constrói dele. Porém, os mesmos aparentam ser impelidos à idade cronológica, baseada no modo de organização capitalista em torno do tempo-espaço (linhas 15-18); uma idade que no discurso jurídico obtém o sentido de juventude, responsabilidade, maturidade (recém-imaturidade), a transição do que é "verde" para o que é "novo" (linhas 7-10).

A FD dos literatos parece realmente ocupar um grande espaço nessa introdução da PC. Tanto o é, que os locutores do texto, ao manterem um considerável número de reiterações em torno da ideia de terra, vestem essa noção de uma literariedade e parecem não perceber os dispositivos de paráfrase que os determinam. Parecem ser eles mesmos fontes do próprio dizer, ignorando sentidos que estão para além do discurso literário ou científico, o que seria entendido como o esquecimento número um - embora, a retomada da noção de "terra" possa ser também o movimento de um elemento do discurso ecológico e não literário (TOCANTINS-SEDUC, 2009, p. 9-10).

O índio, a terra, a natureza e a literatura romântica parecem penetrar essas primeiras palavras na redação da PC (excerto 1), tanto servindo ao propósito de reforço/construção identitária, quanto à organização de um discurso proponente. A seleção dos componentes do discurso que se constrói na PC parece insistir em uma identidade unívoca e que ao mesmo tempo aceita o múltiplo (excerto 1, linhas 1-7; 20-21). Nessa dinâmica, pode-se traduzir a tensão entre subjetivação universal e contraidentificatória. A primeira, como se trata de uma manobra identificatória, requer do sujeito a unidade, a coesão e a coerência (e por isso a

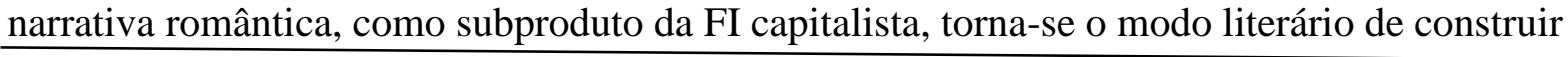


a vida na pós-modernidade). A segunda, como já dissemos, faz-se um pequeno ponto de discórdia (inofensiva e que em nada diminui a eficácia do funcionamento da FI) entre muitos outros dentro da visão capitalista de conceber o mundo.

Essa identidade do Tocantins também pode ter sido erguida através de mecanismos internos ao esquecimento número dois, no qual os sujeitos selecionam os elementos disponíveis de sua FD crendo na univocidade do que dizem, porque, no caráter distintivo da identificação que pensam construir, não acham que haja pluralidade de sentidos.

Até este ponto do texto da PC, não foi possível identificar indícios relevantes do reconhecimento de qualquer outro saber que não o científico. Outras formas de saber não se mostram ao menos como alternativa. Aliás, a noção de alternativa traz consigo a ideia de normalidade, um sentido de norma. Com efeito, o alternativo estaria fora dessa regra, portanto, seria marginal ou subalterno, o que é absolutamente improdutivo conforme Santos (1995) isso se considerarmos uma perspectiva mais solidária, justa e ecológica de valorização dos saberes produzidos pelas diversas comunidades humanas, especialmente aquelas com menos acesso aos exercícios de poder.

\section{A PC: imagens do ensino-aprendizagem de língua inglesa (LI) e (do) seu docente}

Ao iniciar nossos debates sobre os tópicos acima mencionados, somos obrigados a voltar à dialética do ensino médio (EM) propedêutico e àquele do mundo do trabalho. Essas duas vias parecem polemizar as discussões sobre a aprendizagem, bem como orientar a "busca de identidade" desse nível de ensino, como percebemos nas linhas 6-7 do excerto 2 abaixo:

1. Portanto, não se trata de acreditar ingenuamente que orientar seus pressupostos a partir de uma determinada filosofia de educação e definir conteúdos e procedimentos metodológicos apoiados em 5.alguma corrente pedagógica, por si só, sejam condição suficiente para configurar um Ensino Médio que articule as duas dimensões (KUENZER, 2005) e lhe confira a identidade buscada. A compreensão desta relação, portanto, implica reconhecer que não se trata de uma questão exclusivamente pedagógica, ou melhor, esta 10.questão pedagógica está fincada no pantanoso terreno político.

Reiteramos que essa sede de consumo e estabelecimento de identidades (HALL, 1996) é fruto da interpelação capitalista e de uma crise pós-moderna (excerto 3, linha 2-6, adiante) - como nos ensinam Stuart Hall (1995; 1996) e Bauman (2006) -, a qual tirou dos homens e dos objetos a certeza e os lançou na dispersão de um universo multidimensional, que se expande incessantemente. Talvez por isso esse conceito de identidade do EM seja tão almejado do início ao fim da PC - excerto 3:

1.Especialmente em relação ao Ensino Médio, a nova legislação busca alavancar o processo de construção de sua identidade (cuja ausência, não raras vezes, tem gerado crises que acabam por materializar-se da forma mais desastrosa na base em que o processo se desencadeia: a 5.sala de aula), bem como superar a histórica dualidade que caracteriza este nível de ensino.

Lembramos que, na perspectiva da $\mathrm{AD}$, essa busca dos autores da PC pela identidade do ensino-aprendizagem no EM também é reflexo da conformação dos locutores a uma formasujeito universal, configurada pelo rompimento relativo com o teocentrismo e pela injunção 
da juridicidade (sujeito do direito/dever, portanto da lei).

Diante disso, a identidade que a PC tenta constituir para o ensino médio, pretensamente pela superação da dualidade entre trabalho e prosseguimento dos estudos, volta-se novamente para: o vestibular e o mundo acadêmico (excerto 4, linhas 3 e 4, abaixo); a preparação para o trabalho e a cidadania; "compreensão dos fundamentos científicotecnológicos dos processos produtivos", como notado a seguir nas linhas 8-10 do excerto 4:

1.'O Ensino Médio, etapa final da Educação Básica, com duração mínima de três anos, terá como finalidade:

I - a consolidação e aprofundamento dos conhecimentos adquiridos no ensino fundamental, possibilitando o prosseguimento de estudos;

5.II a preparação básica para o trabalho e a cidadania do educando como pessoa humana, incluindo a formação ética e o desenvolvimento da autonomia intelectual e do pensamento crítico;

III - a compreensão dos fundamentos científico-tecnológicos dos processos produtivos, relacionando a teoria com a prática, no ensino 10.de cada disciplina'.

Ao introduzir o elemento da lei que habita o interdiscurso, e mantendo-o afastado da identificação no intradiscurso até certo ponto, a PC admite mais à frente que a educação "deveria garantir ao egresso a continuidade dos estudos, a preparação para a vida e, nela, a garantia da sua inclusão no mundo do trabalho", segundo nossa percepção das linhas 1-4, no excerto 5:

1.então, em tese, estaríamos correspondendo às necessidades dos educandos, como trabalhadores, e às expectativas dos empresários como empregadores e tudo estaria bem. Entretanto, sabemos que as coisas não são assim.

Quando da repetição do dispositivo legal e aparente atitude de superação em relação a ele, achamos se tratar apenas de uma heterogeneidade discursiva mostrada ${ }^{10}$. Mas, além disso, notamos nesse último trecho que a estratégia era apenas uma retomada, um dispositivo parafrásico. O que indicaria novamente o esquecimento número um: os sujeitos da PC, tentam, numa estratégia de contraidentificação, mas não conseguem reconhecer outros elementos que estão para além das FDs que os determinam. Por isso voltam ao conceito jurídico de ensino médio, ainda que claramente não o admitam.

Dessa forma, a educação serviria duplamente ao capitalismo, seja pela via da tecnociência, seja pela profissionalização e empenho direto dos jovens como mão de obra qualificada (TOCANTINS-SEDUC, p. 43): "os jovens como guerreiros vigorosos cuja força e vontade de contribuir seja acolhida e integrada na transformação, para que não se percam na desoladora vereda da autodestruição".

A 'transformação' acima mencionada, se comparada com os outros elementos do intradiscurso, parece ser apenas um mecanismo de manutenção da mesma FI. Dificilmente os sujeitos se desidentificarão de sua forma, rebelando-se contra sua FI.

Reconhecendo a insuficiência do tempo e do espaço na escola os sujeitos da PC pregam uma concepção de ensino-aprendizagem baseada em competências e habilidades, segundo inferimos do excerto 6, linhas 3-7:

\footnotetext{
${ }^{10}$ Mecanismo de inserção interdiscursiva em que a voz do outro deixa marcas evidentes no texto (ver. AUTHIERREVUZ, J. "Heterogeneidade mostrada e heterogeneidade constitutiva: elementos para uma abordagem do outro no discurso". In: Entre a transparência e a opacidade: um estudo enunciativo do sentido. Porto Alegre: Ed. PUC-RS, 2004).
} 
1.Neste enfoque, os conteúdos são tratados em suas distintas tipologias conceituais, procedimentais e atitudinais - e passam à condição de meios para, juntamente com as habilidades e os valores eleitos (éticos), propiciar o desenvolvimento das competências 5.ensejadas, ainda que tenhamos ciência de que pela amplitude e abrangência que tais competências abarcam, o referido desenvolvimento extrapola o tempo e o espaço escolar.

Aliás, cabe-nos notar, antes de abordar essa última questão, que a compreensão a respeito do tempo e do espaço na escola inscrita no documento curricular pode ser fruto da sócio-organização e dos modos de produção impostos pelo capitalismo.

A percepção tão forte quanto à extensão, contração e distensão do tempo parece ter se aprofundado durante a consolidação do capitalismo à época da Revolução Industrial, mais ou menos entre os séculos XVIII e XIX. O Estado-nação liberal e burguês se solidifica e coopera através do modo de produção capitalista para que tempo e espaço sejam segmentados, numerados, controlados, mensurados e contados.

Essa dinâmica se aplica ao tempo porque os processos de produção de bens, mercadorias e serviços passam a ser organizados em uma lógica de maquinário em que o tempo cronológico é ordenado e utilizado racional e maximizadamente, tal qual sugeria as leis da mecânica clássica de Isaac Newton. É assim que por essa época Benjamim Franklin constrói o lema de que tempo é dinheiro, revelando a ligação capitalista indelével entre esses dois elementos (WEBER, 2003).

$\mathrm{O}$ ordenamento do espaço, após a chegada dos Europeus às Índias, ao Oriente e às Américas indicam que o homem agora tinha conhecimento, e, portanto, controle da geografia terrestre. Sem incógnitos presentificados, tempo e espaço são igualmente mensuráveis e também controláveis.

Diante disso, a assunção de que o tempo-espaço não é suficiente para atender às necessidades dos sujeitos, pode indicar quão racionado esse tempo e esse espaço se tornam (excerto 6, linhas 5-7). Uma das razões para esse racionamento pode ser encontrada em motivos econômicos, limitações do aparelho Estatal em oferecer aos seus "cidadãos" essas condições mínimas a um processo crítico-emancipatório (TOCANTINS-SEDUC, 2009, p. 26-27).

Ora, possivelmente mais uma contradição no intradiscurso. A mesma PC que defende a libertação dos sujeitos, admite agora que o tempo-espaço é insuficiente para fazê-lo na plenitude do esperado, pregando assim o ensino por habilidades e competências. Por um lado, a FD de professor-técnico do Estado os impele a prosseguir um discurso motivador e proponente às massas, e para apaziguar as lutas de classe com sentidos de paz e esperança (excerto $7^{11}$ ), de unidade e exaltação das belezas naturais do território empírico (excerto 1 ). $\mathrm{O}$ choque de elementos dessa com a FD técnico-científica faz surgir o modo de funcionamento do imaginário capitalista e a forma deste conceber os lugares e o tempo.

Pode haver também um embate entre o direito-dever da forma-sujeito jurídico e os propósitos da FI que o determinam. Isso mais uma vez pode ter sido causado pelos pontos de discórdia que FD científica cria no seio do ideário capitalista, como a formação de novos saberes e ideais acerca de justiça, equidade, oportunidade, solidariedade, redistribuição de renda, educação, tolerância e respeito. Por isso os locutores da PC dizem reivindicar uma educação libertadora - que "a nova legislação busca alavancar" (excerto 3, anterior, linhas 1 e 2) -, quando pretensamente não podem implementá-la, ao menos não através do Estado que

\footnotetext{
${ }^{11}$ Este documento pretende contribuir, portanto, com a Esperança, a esperança cujas condições de concretização, se não existentes, precisam ser criadas [...] (TOCANTINS-SEDUC, 2009, p. 13).
} 
os rege, e do tempo e espaço insuficientes. Notamos que nessa situação também opera o modo de subjetivação universal passiva e o esquecimento número dois, pelos quais o sujeito acreditase coeso e coerente, quando os diversos valores contidos na dispersão das FDs o empurram inevitavelmente para a contradição.

Para além disso, e obviamente, a PC usa os interesses econômicos na esfera do Mercado Comum do Sul, e o poder capitalista e hegemônico dos países de língua inglesa para respectivamente justificar o prestígio/escolha do espanhol e do inglês. Observe-se que enquanto aquele é optativo - provavelmente porque o Brasil mantém relações econômicas menos impositivas com os países que o utilizam ${ }^{12}$ - este é obrigatório - dado o poderio político das nações que o tem como idioma oficial, que investem maciçamente em sua propagação (TOCANTINS-SEDUC, 2009, p. 187).

A FI interpela nos sujeitos a concepção de língua como capital, de certo modo. Língua é 'poder', e por essa razão o inglês se mantém no currículo escolar e foi a única considerada, dizem os locutores da PC (idem, p. 183) - visto que o espanhol seria implementado posteriormente (idem, p. 184). Não podemos esquecer, que essas posturas surgem como ressonância das ações políticas propostas pelo Banco Mundial e, indiretamente, pela própria UNESCO, como apontamos na abertura deste trabalho.

Subjazem a esses deslizes, ou retomadas que deixam escapar o ato falho, outras incongruências que constituem o intradiscurso em um movimento exo-endomórfico. Ao lado da visão de linguagem como "eixo de comunicação e interação" (idem, p. 143), como "espaço dialógico" (idem, p. 144), "bem cultural", escapam sentidos de uma língua como "ferramenta", sujeita aos polos certo e errado ou à 'correção'. Na verdade, ensinar os alunos a falar "corretamente" uma língua (idem, p. 190-191) parece ser um dos objetivos que escapa na série de deslocamentos de sentido na PC.

Quanto à abordagem de ensino da LI, parece prevalecer a comunicativa interacional aliada ao conceito de letramento (idem, p. 186). Porém, observamos que o conceito de letramento que se insere na $\mathrm{PC}$ parece restringir-se à categoria autônoma ${ }^{13}$, tão preciosa às leis de mercado (idem, p. 144), já que a desidentificação discursiva e a viragem ideológica (mecanismos que permitiriam aos sujeitos dizer o oposto, defender mais abertamente o letramento crítico) podem ser consideradas um incômodo/ameaça à manutenção da dominação capitalista.

Apesar desse discurso sobre abordagem comunicativa, no cotidiano docentes de inglês são obrigados a seguir uma tabela denominada de conteúdos mínimos (anexo à PC). Seu acompanhamento na nossa escola-campo é rígido do ponto de vista formal, e nos discursos de gestores não parece ser apenas sugestão, como aponta a PC.

Evidente que, no que se refere a essa questão, surge um embate entre dois discursos sob a mesma FD. Aquele que determina o corpo técnico-docente do Estado, e outro que perpassa a vida do professor profissional liberal ou servidor público. O conflito de interesses parece bastante latente, e o aparelho estatal entra em cena para representar o terceiro partido da disputa, que com sua rede institucional acaba por se impor, de certo modo, aos sujeitos de outras classes - assim, os conteúdos mínimos não são problematizados pelos autores da PC, resta-lhes o silêncio.

A despeito dessas e de outras condições de ensino, a PC parece dar mais prevalência

\footnotetext{
${ }^{12}$ Ver. CAMARGO, S. de. Mercosul: crise de crescimento ou crise terminal? Lua Nova, São Paulo, vol. 1, n. 68, p. 57-90, 2006.

${ }^{13}$ Sob o viés do letramento autônomo, a escolarização é quase sempre assumida como um processo grafocêntrico, essencial e simultâneo ao letramento (KLEIMAN, 2008). Isolado por sua natureza técnica e neutra, esse modelo é dedicado ao aprimoramento gradativo do pensamento abstrato/lógico, o que pode conduzir a um ensinoaprendizagem enaltecedor da erudição, da escrita, e da cognição. Com efeito, surge uma separação absoluta entre os sujeitos que sabem e os que não sabem ler/escrever.
} 
à modalidade oral do que a escrita (TOCANTINS-SEDUC, p. 192-193). Do ponto de vista da abordagem comunicativa, essa predominância parece ser fruto de um forte alinhamento teórico; do ponto de vista prático e do real contexto, talvez nem tanto, já que a demanda pelo uso oral da língua inglesa pouco se faz notar no cotidiano.

Por fim, abordaremos a imagem do professor nesta PC e, quando possível, sua relação com o processo ensino-aprendizagem.

Sob o conceito de 'utopia' (idem, p. 42), a PC vai entretecendo a imagem do docente. A polissemia dessa palavra no contexto da PC é extremamente fecunda. E é sob seu manto significativo que a PC o vai concebendo como 'intelectual transformativo' (idem, p. 38), ativista social, agente político (idem, p. 38), trabalhador social ou reacionário (na visão freiriana, idem, p. 39), militante da justiça social e pesquisador da sala de aula (idem, p. 41).

Em virtude desse quadro, é possível supor a dificuldade, mas não a impossibilidade, de que os professores assumam essas representações de sua identidade profissional com vista à mudança social sem antes conseguir mudar a sua própria situação.

Ao contrário do discurso pedagógico, a FD do professor (o profissional cotidiano) nem sempre comporta a utopia ou o sonho de transformar o mundo. Parece-nos que ao longo da história esses elementos foram perdendo espaço nessa formação. Em seus discursos esses são componentes pouco compreendidos, ou cujas implicações e suscitações podem ser extremamente negativas e depreciativas.

A PC imagina um professor que transforma a sociedade, e outro que apenas reproduz sua organização - é o que depreendemos da tabela bastante extensa de conteúdos mínimos, anexo à PC, para o decurso de 3 anos com 1 ou raramente 2 aulas semanais -; um docente ativista/militante político, e outro que apenas exerce sua profissão, no sentido mais elementar e material. Contudo, elege-se como ideal aquele que "desenvolve um entendimento sistemático das condições que configuram, limitam ou potencializam sua ação"; e mais que isso, aquele que tem o dever de se "assentar sobre o bom julgamento, ilustrado pelo saber" (idem, p. 40); que a partir da práxis em sala de aula (idem, p. 189) aplica-se à "utopia da construção de um novo mundo onde a cidadania e a verdadeira competência sejam evidenciadas" (idem, p. 42).

Algumas opacidades se formam quando os locutores da PC constroem essas imagens do professor: primeiro não temos clareza do que seja o "bom julgamento"; segundo, não há certeza sobre o que seja essa "verdadeira competência". Enquanto aquele parece ter sido originado no universo moral, este parece ligado aos discursos clássicos sobre ciência enquanto verdade a ser perseguida, conforme sugerimos antes.

Pelos atributos da polissemia, bem como pelas possibilidades abertas mediante o esquecimento número dois, o professor representado na PC parece ficar entre o ativismo sóciopolítico, o julgamento das virtudes morais (bom, mal, certo, errado) e a busca pela verdade que a ciência, movida pelo conceito de competência (ou competição), pode oferecer. Talvez essa seja a imagem discursiva de um personagem utópico, no sentido do impossível; no sentido de que conformada à forma jurídica pós-moderna apenas uma vertente se lhe apresente, a do dever e não a do direito.

Do ponto de vista da luta de classes, isso parece ser compreensível. Muito mais que direitos, ao proletariado são impostos encargos e responsabilidades que, na maioria das vezes, sustentam a prevalência da burguesia e mantêm a massa trabalhadora dentro dos limites que o capitalismo prevê. Com a contração do tempo ou a insuficiência dele, e sob as urgências do trabalho, não há espaço para refletir sobre a própria condição. Reiteramos que o 'libertador' que não pode pôr livre a si mesmo, porque está absorto no trabalho que a FI lhe impõe, dificilmente conseguirá libertar o outro.

A atmosfera idílica da abertura do texto é retomada em certo ponto das seções que 
tratam do docente de LI (TOCANTINS-SEDUC, 2009, p. 43). Desta vez o contraste parece ser maior, não apenas porque se trata de um gênero discursivo formal, no qual não se espera literariedade, mas também porque os mecanismos de reprodução do capital e suas emergências parecem contrastar com certas imagens da literatura romântica, que transforma os educandos em "jovens guerreiros vigorosos" e os professores em "momentâneas certezas no mar das incertezas"; e o Tocantins, antes genuíno, agora é terra de peregrinos (idem, p. 42-43), fonte que sacia a sede destes.

Por fim (TOCANTINS-SEDUC, 2009), como uma influência do discurso mecanicista de ciência, entrecruzado ao literário, todos passam a ser designados como poetas, artistas criadores e multiplicadores de energia, seguidores das leis do universo; que sob o discurso da complexidade excedem o conceito de máquina, para se lançarem na concepção de caos, desordem e organização sistêmica aberta e entrópica, auto-recursiva.

\section{Considerações finais}

É possível observar que tanto os PCN (BRASIL, 1998) quanto a PC representam o reconhecimento de algumas dificuldades enfrentadas no ensino de língua estrangeira. No entanto, poderíamos notar que a PC procura silenciar críticas diretas ou menções à situação contemporânea do ensino de LI no Tocantins. Foram silenciados na PC aqueles debates todos, citados na introdução de nosso trabalho, acerca dos índices de desempenho do estado no ENEM. Ademais, foram ignorados os argumentos em torno do fato de que "não se ensina inglês pra valer" na escola ${ }^{14}$, por exemplo; ou a ideia tão famigerada de que os estudantes saem das escolas públicas ou privadas sem o domínio esperado das habilidades de compreensão e produção, seja oral ou escrita - conforme sugerem pesquisas do British Council no Brasil ${ }^{15}$.

De fato, o documento raramente expõe algum enunciado através do qual seja possível reconstruir os sentidos atribuídos ao ensino de LI por professores da rede pública estadual ou pelo senso comum do tocantinense. Muitos poderiam argumentar que em uma PC, em virtude de sua natureza, não seria fácil encontrar referências às práticas reais de ensino da língua. Porém, nem mesmo nas primeiras páginas do documento, nas quais se expõe uma espécie de panorama da educação tocantinense, é possível encontrar sinais disso. As inúmeras reiterações, paráfrases e transposições textuais de outros documentos nacionais fazem da PC tocantinense um território árido para acolher as vozes das centenas de professores do Estado, na medida em que os discursos científico e literário ocupam os espaços que poderiam ser alocados para os sujeitos-docentes (ou discentes) cotidianos e seus posicionamentos.

Parece-nos que nela, em detrimento do espaço do dizer docente, privilegia-se o da FD considerada científica. Diferentemente dos PCN (BRASIL, 1998), a PC não parece procurar relacionar as vozes das salas de aulas com os longos enunciados teóricos das academias ou com a prosa de José de Alencar, ou mesmo a poesia de Fernando Pessoa.

Independentemente das razões, o que pudemos notar foi a abertura bastante significativa para o discurso literário, sobretudo no início do documento. E como seria de se esperar, valores desse mesmo discurso são retomados ao longo do texto. Quando não, é possível notar, através de deslocamentos, a transição entre um e outro, ou seja, entre o científico e o literário. Com efeito, o ensino de língua inglesa em sua dimensão concreta é alçado a um estágio mais abstrato, ressignificado em forma de expectativa, na medida em que não se cede espaço para as vozes do cotidiano escolar.

\footnotetext{
${ }^{14}$ Coordenadora do INEP declara que "no ensino médio não ensina pra valer as línguas estrangeiras" - fonte: < http://www1.folha.uol.com.br/folha/educacao/ult305u3798.shtml>.

${ }^{15}$ Ver. BRITISH COUNCIL. Ensino de inglês na Educação Pública Brasileira. São Paulo: BC, 2015.
} 
Grosso modo, diríamos que se trata de um projeto de futuro que, de certa maneira, está suspenso no mundo literário e/ou científico, além de negligenciar os discursos da gente que constrói a educação do presente e do passado. Questionamo-nos se é essa espécie de projeto a mais proveitosa para promover uma educação engajada com os problemas educacionais reais ou concretos da gente do Tocantins, para além dos índices do ENEM, mas sem, contudo, desconsiderá-los.

Ao ensino de língua inglesa são atribuídos os valores da independência intelectual, redimensionamento cognitivo e político-ideológico, trabalho, formação humana e oportunidades de mobilidade geocultural. A possibilidade de que o estudante selecione o idioma que deseja estudar parece que não obtém relevância, e são os autores que escolhem e justificam que idioma deve ser ensinado/aprendido na escola. Nesse sentido, as vozes dos estudantes são também silenciadas, e a expectativa de que se construa uma escola mais democrática perde ainda mais vigor. Embora seja mais perceptível na PC uma tendência a certo utilitarismo da língua, essa inclinação perde força por causa da interferência da FD em sua vertente da Complexidade, que, por sua vez, chama a atenção para fatores mais humanistas.

Perpassados pela FI capitalista, os autores da PC buscam no sistema econômico (ou no uso/utilidade) as respostas para os porquês do ensino de LI no Tocantins - confirmando discursos do FMI e do Banco Mundial. Outrossim, adiciona à margem dessa postura a função propedêutica do Ensino Médio, tão comumente imputada a esse nível escolar, e provavelmente popular entre muitos docentes.

A PC também parece apontar o inglês como forma de acesso a bens culturais. Como vivemos em uma sociedade/escola capitalista ainda preconceituosa, excludente e elitista, poderíamos entender aqueles "bens culturais" como sendo os clássicos literários, produções científicas e obras eruditas diversas. Esse quadro, na verdade um simulacro, seria estranho ao uso do inglês em situações de lazer e informalidade.

Como a $\mathrm{AD}$ nos ajuda a entender, na PC há fortes alterações de posição. Ora a identidade dos sujeitos escritores surge como desejo de inteireza, unidade, como centralização em torno da adoção da Teoria da Complexidade; ora se reprojeta com nuances visionárias e encanto literário; ora é tomada pela incerteza e pela dispersão; ou às vezes ressurge novamente com características de univocidade.

Nos limitados momentos dedicados a abordar a práxis-didático pedagógica em sala de aula, percebemos que o discurso da PC silencia a voz docente e discente no que diz respeito à vida escolar, porquanto a voz dos teóricos preenche maior espaço. Como consequência, a Teoria da Complexidade, anteriormente defendida quanto à contextualização real da educação e sua democratização, parece perder força agora. A PC da introdução não parece a mesma do embasamento teórico, tampouco o seria na apresentação de aspectos e sequências didáticas.

Essas seções do gênero textual da PC parecem ter suas próprias características, seu próprio histórico, seu próprio modo de organização. Tais elementos promovem ainda mais o esquecimento número dois, e a PC prima pela FD científica na tentativa de submeter boa parte dos valores advindos de outras FDs. É como se quase todo dizer devesse ser referendado pelo crivo da ciência, um saber à parte.

$\mathrm{O}$ esquecimento número um exercita-se em uma posição assumida na abertura da PC que põe os sujeitos escritores do documento no lugar de motivadores, fundadores/reveladores da identidade da comunidade local. A partir do modo como a FD artística/literária domina os tons dos dizeres nessa parte do gênero, podemos afirmar que no avesso de todo o louvor prestado à construção identitária tocantinense, encontraríamos um estado periférico, o último no ENEM, "sem identidade", sem maturidade ou representatividade. Este mesmo estado estaria disperso pela liquidez da imigração, sem a 
âncora da história linear para fincar no tempo as colunas do "quem sou", "por que sou" e "para onde vou", que tanto atormentam o homem, e que tanto o fazem se lançar na aventura da linguagem e da vida em busca de seus sentidos e significados.

É no dizer da prosa de Alencar, que surgem as figuras do índio e do guerreiro. Em manobra de retomadas, metáforas e paráfrases a PC torna-se agora o cenário para que a narração original surja do oculto e revele o que todos precisam saber: quem somos nós? É na cadência das partes do enunciado que a PC sugere que encontremos a narrativa capaz de responder a essa intrigante pergunta. Apesar de tratar-se de um texto muito mais descritivoargumentativo do que narrativo, podemos dizer que seu cunho coletivo-biográfico está presente e faz surgir o Tocantins como um sistema de significação no qual cada tocantinense deve alçar sua existência-identitária.

Pelas lentes da psicologia social (POLLAK, 1992) notamos a FI capitalista impulsionando estes movimentos: a construção da unidade físico-identitária, isto é, o sentimento de fronteiras tangíveis e definidas (no nosso caso os rios Tocantins e Araguaia) ou até a sugestão de mútuo pertencimento aos que se encontram nesses limites (todos somos professores, servimos ao mesmo povo, como um só povo, em uma só terra, sob o mesmo governo); o reforço da ilusória consciência de continuidade dentro da fluidez temporal (nas referências e retomadas que a PC faz posicionando-se no ontem, no hoje e, principalmente, na esperança do amanhã). E, por fim, o sentimento de coerência, de efetiva unificação do serexistir proporcionado pelo esquecimento número dois, que já tantas vezes temos mencionado.

Esses deslocamentos indicam a auto e alter-discursivização, e são característicos dos sujeitos sociais (no nosso caso, os redatores da PC) compelidos a se reconhecerem em todas as passagens. Para tanto, procuram manter determinados traços discursivos a fim de se enxergarem, conectarem-se ao corpo social e simultaneamente se destacarem da multidão de tantos outros documentos, construindo assim o seu "perfil” (KEHL, 2012).

\section{Referências}

ARAÚJO, G. A. Representações sobre o ensino-aprendizagem de língua inglesa: entre os documentos oficiais e a fala do professor da escola pública. 2014. 183 f. Dissertação (Mestrado) - Programa de Pós-Graduação em Letras, Universidade Federal do Tocantins, Araguaína, 2014.

ASSEMBLEIA LEGISLATIVA-TO. Deputados debatem sistema educacional do estado. Palmas: Dicom, 2008a. Disponível em: <http://www.al.to.leg.br/noticia/1697/>. Acesso em: 29 jul. 2013.

. Educação volta a ser debatida na assembleia. Palmas: Dicom, 2008b. Disponível em: < http://www.al.to.leg.br/noticia/1800/>. Acesso em: 04 ago. 2013.

Requerimento no 6598/2008, da Dep. Luana Ribeiro. Palmas: Dicom, 2008c. Disponível em: <http://sapl.al.to.gov.br/sapl/materia/5117>. Acesso em: 04 ago. 2013.

BAKHTIN, M. M. Estética da criação verbal. 2 ed. São Paulo: Martins Fontes, 1997.

BANCO MUNDIAL. Educação primária. Documento de política do Banco Mundial. Washington: BM, 1992.

. Prioridades e estratégias para a educação. Washington: BM, 1995.

BAUMAN, Z. Liquid Modernity. 6ª imp. Malden: Polity Press, 2006.

BRASIL, Ministério da Educação. Parâmetros Curriculares Nacionais. Brasília: MEC, 1998.

. Desempenho médio do Enem 2006. Brasília: SEB, 2007. 
DENZIN, N. K. et al. "Disciplining qualitative research". International Journal of Qualitative Studies in Education, Indianapolis, vol. 19, n. 6, p. 769-782, nov. 2006.

G1 NOTÍCIAS. Resultado do Enem-2007 foi 40\% melhor que ano anterior. Rio de Janeiro: Organizações Globo, 2008. Disponível em: <http://g1.globo.com/Noticias/Brasil/0,,mul387338-5598,00-resultado+enem.html>. Acesso em: 05 ago. 2013.

Veja o resultado do Enem 2009. Rio: OG, 2010. Disponível em: $\overline{<\mathrm{http}: / / g 1 . g l o b o . c o m / v e j a-o-r e s u l t a d o-d o-e n e m-2009 . h t m l>. ~ A c e s s o ~ e m: ~} 05$ ago. 2013.

GRIGOLETO, E. O movimento de desidentificação do sujeito: uma reflexão a partir de Semântica e Discurso. In: Anais do I Seminário de Estudos em Análise do Discurso. $1^{\mathrm{a}}$ ed. 2003. Anais. Porto Alegre: UFRGS, p. 1-7.

HALL, S. "Who Needs 'Identity'?" In: DU GAY, P.; HALL, S (org.). Questions of Cultural Identity. $2^{\mathrm{a}}$ imp. London: Sage Publications, 1996.

. et alii (org.). Modernity: An introduction to modern societies. Oxford: Blackwell Publishers, 1995.

KEHL, M. R. Minha vida daria um romance. Disponível em: <http://www.mariaritakehl.psc.br/>. Acesso em: 05 ago. 2012.

KLEIMAN, A. B. Preciso "ensinar" o letramento? Não basta ensinar a ler e a escrever? Campinas: UNICAMP/MEC, 2005.

LAKATOS, E. M.; MARCONI, M. de A. Fundamentos de metodologia científica. São Paulo: Atlas, 1993.

MARX, K. Capital (A Critique of Political Economy): The Process of Production of Capital. Vol. I. New York: International Publishers, 2010.

MORIN, E. Introdução ao pensamento complexo. $5^{\mathrm{a}}$ ed. São Paulo: Inst. Piaget, 2008.

. O método I: a natureza da natureza. $2^{\mathrm{a}}$ ed. Lisboa: Publicações Europa-América, 1987.

ORLANDI, E. "Discurso, imaginário social e conhecimento”. Em Aberto, Brasília, vol. 1, n. 61, jan./mar. 1994.

. Gestos de leitura: Da história no discurso. Campinas: Unicamp, 1997.

. "A leitura e os leitores possíveis". In: ORLANDI (org.) A leitura e os leitores. Campinas: Pontes, 1998.

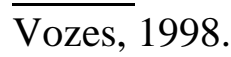

. Interpretação: autoria, leitura e efeitos do trabalho simbólico. $2^{\mathrm{a}}$ ed. Petrópolis:

. Análise de discurso: princípios \& procedimentos. Campinas: Pontes, 1999.

. "O inteligível, o interpretável e o compreensível". In: ZIBERMAN, R.; SILVA, E. (orgs). Leitura: perspectivas interdisciplinares. São Paulo: Ática, 2002.

PÊCHEUX, M. Semântica e discurso: uma crítica à afirmação do óbvio. Trad. de E. P. Orlandi et alii. Campinas: Unicamp, 1995.

. “Análise Automática do Discurso". In: GADET, F.; HAK, T. (Orgs.) Por uma Análise Automática do Discurso: uma introdução à obra de Michel Pêcheux. Trad. de E. P. Orlandi. Campinas: Unicamp, 1997. . O Discurso - estrutura ou acontecimento. Campinas: Pontes, 2006. 
POLLAK, M. "Memória e identidade social”. In: Estudos Históricos, Rio de Janeiro, vol. 5, n. 10, p. 200-215, 1992.

SANTOS, B. de S. Um discurso sobre as ciências. $7^{\text {a }}$ ed. Lisboa: Afrontamento, 1995.

STÁLIN, J. V. Sobre o materialismo dialético e o materialismo histórico. Rio de Janeiro: Edições Horizonte, 1945.

SYMONIAK, J. "The Washington consensus". New Voices in Public Policy, Fairfax, vol. 5, n. 1, p. 2-20, 2010/2011.

TOCANTINS-SEDUC. Proposta Curricular do Tocantins para o Ensino Médio: Versão Preliminar. Palmas: Dicom, 2009.

UNESCO. World declaration on education for all and the framework for action to meet basic learning needs. Tailândia, 1990. . O marco de ação de Dakar Educação para Todos. Dakar, 2000.

WEBER, M. A ética protestante e o espírito do capitalismo. São Paulo: Pio. T., 2003.

Recebido em 18 de setembro de 2018

Aceito em 20 de dezembro de 2018 